have put the issue on the table and I feel we are on our way to resolution," he says.

The situation has caused leaders in the microbicide field to renew calls for better ways of reviewing and coordinating trial plans. Scientists in the field already share and discuss ideas and data through formal and informal meetings, but there is no mechanism for reviewing and disseminating plans for clinical trials. This means that institutions sometimes run redundant trials that are not always backed by good evidence, says immunologist John Moore of the Weill Cornell Medical College in New York.

"Historically, the microbicide field has gotten it wrong by doing multiple simultaneous trials of similar products, and the CAPRISA episode represents a boiling-up of frustration in the field," Moore says.

The study had already been approved by many bodies - including the South African Medicines Control Council, and ethics review boards convened by the University of KwaZuluNatal and by Family Health International, the group that is running the trial. USAID staff decided to grant funding for the study in April after conducting its own internal review, says Jeff Spieler, senior science adviser in USAID's office of global and reproductive health.

But few preclinical results have been made publicly available, leaving scientists and advocates uneasy about the trial. Normally, the development of a product such as a microbicide would be sponsored by a private company, which would not be obligated to consult the public beyond regulatory agencies. But such companies are not interested in developing microbicides because they are aimed at poor people, so the field is funded largely by limited public resources. Advocates argue that this means the public deserves full access to all the relevant data.

"We need a transparent, accessible and international mechanism of peer review and reflection for making decisions that are of fundamental importance to the microbicide field," says Lori Heise, director of the Global Campaign for Microbicides, an advocacy group based in Washington DC.

Spieler says USAID has decided to consult external reviewers for future trials. And the National Institutes of Health's Office of AIDS Research is setting up a microbicide working group. But it is not clear whether this will include a broad enough range of international expertise to ensure that good decisions are made, Heise says. And others say the field is already facing a crucial turning point.

"The microbicide field is drinking in the last-chance saloon," Moore says. "If it has many more problems, it's finished."

Erika Check

\section{Conserving life and livelihood}

Last week, more than 1,600 people involved in conserving Earth's flora and fauna came to Port Elizabeth, South Africa. It was the first time that the Society for Conservation Biology, based in Arlington, Virginia, had met in Africa, and the setting raised a challenging question: does conservation help poor people?

Some researchers think that conservation work will naturally and inevitably benefit local people, because it will sustain resources over time. But conserving animals and plants often means restricting access to them. And as Yaa Ntiamoa-Baidu, a Ghanaian conservationist, asked those gathered at the opening plenary session: “Do your conservation projects make a difference in village life in Africa?"

To try to get some data with which to answer her own question, Ntiamoa-Baidu, who works with the conservation group WWF and the Ghanaian government, looked at 50 projects in Africa. Of the project managers surveyed, $92 \%$ thought that they were making a difference on the community level. But projects that tried to measure the effects - such as a wetland conservation project in Ghana that measures the number of new enterprises created by an eco-tourism effort - were few and far between. Hardly any of the 50 projects had any built-in way to quantify or demonstrate their benefits. "Why is it that we do not have concrete data to support this?" Ntiamoa-Baidu asked. In a session on the link between conservation and poverty, Peter Kareiva of Seattle, Washington, chief scientist at the Nature Conservancy, presented an analysis of almost 200 development projects run by the World Bank, some of which had environmental components. Encouragingly, he found that development projects with built-in conservation goals were no less effective than those without them, as measured by the World Bank's evaluations. But his data do not address the issue of how effective conservation projects are if they include specific development goals in their remit.

Many hope that local researchers will take the lead on conservation projects. "If Africans have the empowerment and the tools, they will have to make these decisions themselves," says Jonathan Adams, also of the Nature Conservancy. In South Africa, there are hopes that more black people will take careers as conservation scientists. According to Brian Huntley, an environmental adviser to the South African government, black conservation scientists are only now starting to emerge, more than a dozen years after the end of apartheid, and he thinks that their number will increase exponentially.

But for many South Africans, continued poverty and the lingering social effects of apartheid are daunting obstacles to such a career. "When we were kids, we weren't allowed to go to the aquarium or anything like that, so how were we to learn that saving nature was important?" asks Mncedi Nkosi, a young, black, freshwater ecologist at Ezemvelo KZN Wildlife, a province-level public-private conservation group. "Most people still are more worried about socioeconomic issues, and they don't really understand what I do. I sometimes just say that I clean water for a living."

About one-third of the 700 papers and posters at the conference were presented by Africans, according to the meeting's organizer, Graham Kerley.

Emma Marris

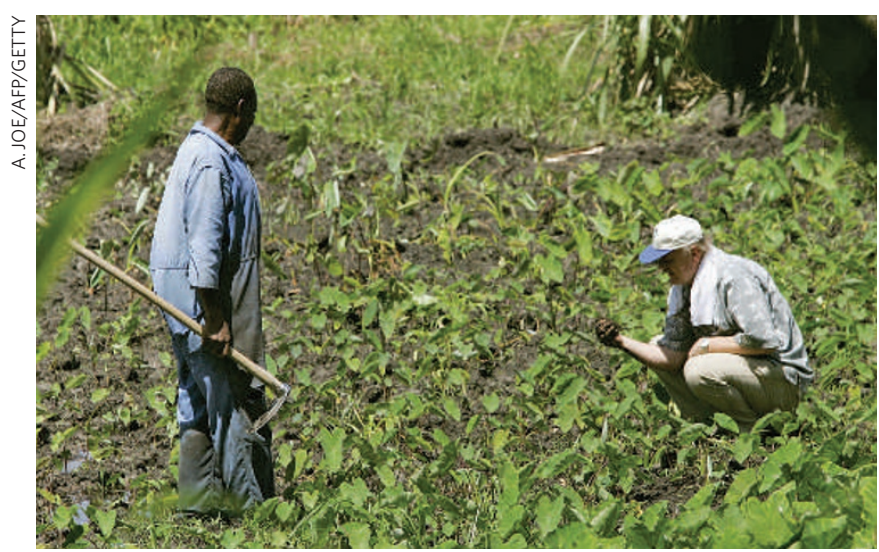

Few development projects measure the effects they are having on village life. 